\title{
EFFECT OF DENSITY OF FUELS ON THE OPERATIONAL AND ECOLOGICAL CHARACTERISTICS OF MOTOR VEHICLES
}

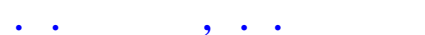

лючевые слов : плотность топлив ; эксплу т иионные и экологические х $p$ ктеристики втомобилей; нефтеперер ботк ; прис дки ктоплив м

Key words: density of fuel; operational and ecological characteristics of motor vehicles; oil refining; fuel additives

епрерывно р стущий мировой втоп рк является одним из основных потребителей нефтепродуктов. роцесс эксплу т ции втотр нспорт неизбежно связ н с ростом сопутствующих потреблению топлив эмиссий токсичных веществ, с жи и п рниковых г зов, н современном эт пе втомобили являются одним из основных источников 3 грязнения окруж ющей среды [1]. зн чительной степени экологические х р ктеристики и энергоэффективность эксплу т ции втомобилей связ ны с к чеством применяемых моторных топлив, которое является лимитирующим ф ктором при попытке решения проблемы обеспечения экологической безоп сности эксплу т ции втомобилей метод ми совершенствов ния конструкции двиг телей и втомобилей, совершенствов ния системы поддерж ния р ботоспособности, дорожной сети и упр вления движением.

чество моторных топлив в зн чительной степени определяется его плотностью - легко определяемым и контролируемым п р метром к честв нефтепродуктов. елесообр зно р ссмотреть влияние плотности н экологические и эксплу т ционные

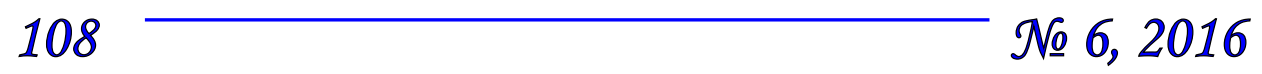


$\mathrm{x}$ р ктеристики втомобилей. то созд ет н учную основу для обоснов ния комплекс технологических мер повышения экологической безоп сности и эффективности втотр нспорт, основ нной н влиянии н плотность моторных топлив.

блии 1 висимость удельных выбросов диоксид углерод от плотности моторных топлив. иоксид углерод является неизбежным продуктом сжиг ния топлив .

бъективной $\mathrm{x}$ р ктеристикой моторного топлив относительно выделения диоксид углерод при его сжиг нии является отношение обр зов ния диоксид углерод к получ емой энергии.

т блице 1 приведены результ ты р счет выделения диоксид углерод при сгор нии р зличных углеводородов в состоянии иде льного г з при 300 , продукты горения выбр сыв ются при 900 , использов ны термодин мические д нные [2].

ибольшее удельное выделение диоксид углерод д ет бензол, н именьшее проп н, выделение диоксид углерод для бензол $\quad$ н $23 \%$ больше, чем для проп н . ля лк нов, лкенов и цикло лк нов удельное выделение диоксид углерод дост точно близко (63,8 - 70,8 мг/к ж), для ром тических углеводородов оно зн чительно выше, для углеводородов $\mathrm{C}_{6}-10-82,7-78,0$ мг/к ж. дельное выделение диоксид углерод удовлетворительно коррелирует с плотностью углеводородов (рис. 1).

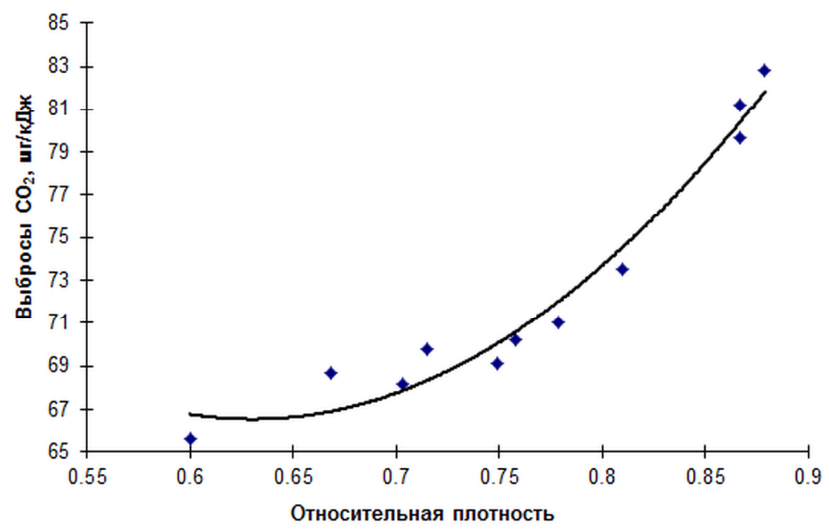

ис. 1. висимость удельного выделения 2 от плотности углеводородов

ля спиртов и эфиров удельное выделение диоксид углерод т кое же, к к у лкенов и цикло лк нов (т блиц 2).

ля моторных топлив теплот сгор ния с удовлетворительной точностью (ошибк менее $0,2 \%$ ) определяется по формуле . сс с попр вкой . . осиков [3]

$$
\mathrm{Q}_{\mathrm{H}}=49907-8552 \rho_{4}^{20}, \mathrm{~K} \text { ж/КГ . }
$$


дельное выделение диоксид углерод при сгор нии спиртов и эфиров

\begin{tabular}{|c|c|c|}
\hline опливо & еплот сгор ния, & $\begin{array}{c}\text { дельное выделение } \\
\text { к ж/кг }\end{array}$ \\
\hline етиловый спирт & 21486 & 64,0 \\
\hline зопропиловый спирт & 31655 & 69,5 \\
\hline иэтиловый эфир & 34611 & 68,7 \\
\hline трет- утиловый спирт & 33677 & 70,7 \\
\hline етил-трет-бутиловый эфир & 35838 & 69,7 \\
\hline
\end{tabular}

ссчит но по д нным [2]

ереведя $\rho_{4}^{20}$ в $\rho_{15}^{15}$ с использов нием формулы . . ус ков по ур внению $\rho_{15}^{15} \approx \rho_{4}^{20}+0.0035$ [4] для р счет теплоты сгор ния, получим ур внение (2)

$$
\mathrm{Q}_{\mathrm{H}}=49936,9-8552 \rho_{15}^{15}, \mathrm{~K} \text { ж/Кг . }
$$

одерж ние углерод определяется по эмпирической формуле рэг (3) [5]

$$
=74+15 \rho_{15}^{15}, \% \text {. }
$$

ри сжиг нии топлив с т ким содерж нием углерод удельное обр зов ние диоксид углерод $W_{\mathrm{CO}_{2}}$ в $\mathrm{p}$ счете н тонну топлив сост вит:

$$
W_{\mathrm{CO}_{2}}=0,01 \cdot\left(74+15 \rho_{15}^{15}\right) \cdot \frac{44}{12}=0,55 \cdot\left(4,93+\rho_{15}^{15}\right), \text { т/ т топлив }
$$

и удельное выделение диоксид углерод $\mathrm{H}$ единицу получ емой при сжиг нии топлив энергии определим по ур внению

$$
\frac{\mathrm{W}_{\mathrm{CO}_{2}}}{Q_{\mathrm{H}}}=64,31 \frac{4,93+\rho_{15}^{15}}{5,83-\rho_{15}^{15}}, \mathrm{Mг} / \mathrm{K} \text { ж. }
$$

рис. 2 ( ), (б) приведены эти линейные 3 висимости удельного выделения диоксид углерод от плотности моторного топлив $\frac{\mathrm{W}_{\mathrm{CO}_{2}}}{Q_{\mathrm{H}}}$ при изменении плотности изменяется в большей степени, чем $W_{\mathrm{CO}_{2}}$, поскольку $\mathrm{Q}_{\mathrm{H}}$ с увеличением плотности уменьш ется. ким обр зом, чем меньше плотность моторного топлив , тем меньше выбросы диоксид углерод $\mathrm{H}$ единицу получ емой при его сжиг нии энергии (для двиг теля д нного тип ). лотность топлив возр ст ет с ростом содерж ния непредельных и ром тических углеводородов, что приводит соответственно и к росту удельных выбросов диоксид углерод .
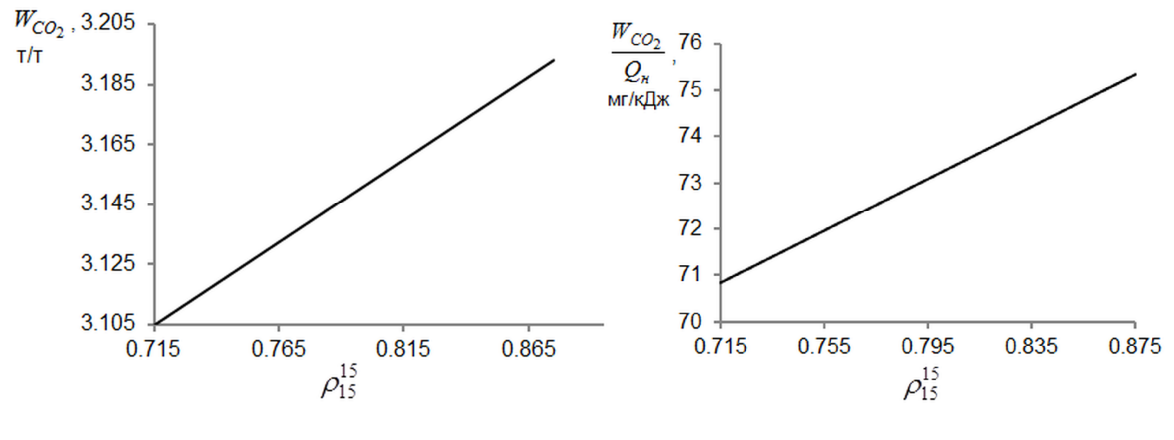

ис. 2. висимость удельного выделения

$$
\text { (a) } W_{C O_{2}}=f\left(\rho_{15}^{15}\right) ;\left(\text { (б) } \frac{\mathrm{W}_{C O_{2}}}{Q_{\mathrm{H}}}=f\left(\rho_{15}^{15}\right)\right.
$$


висимость выбросов оксидов углерод и зот от плотности моторных топлив. нее втор ми было пок 3 но [6-10], что при сгор нии стехиометрической смеси углеводород $\mathrm{C}_{n} \mathrm{H}_{2 n-x}$ с воздухом м ксим льн я темпер тур в пл мени возр ст ет тем больше, чем больше $x, 3$ счет уменьшения количеств продуктов сгор ния, несмотря н то, что теплот сгор ния в к ж/моль при этом сниж ется. ри этом величин р зогрев продуктов сгор ния $\Delta T$ определяется по уст новленному втор ми соотношению

$$
\Delta T=\frac{Q_{H}}{\sum m_{i} c_{i}}=\frac{613 n-103 x}{(287 n-53,5 x) \cdot 10^{-3}}=2135 \frac{n-0,168 x}{n-0,186 x},
$$

где $m_{i}$ - число молей, $c_{i}$ - теплоемкость продуктов сгор ния. ким обр зом, м ксим льный р зогрев достиг ется для ром тических углеводородов, имеющих н ибольшую плотность. величение содерж ния в топливе непредельных и ром тических углеводородов, и соответственно, плотности ужесточ ет темпер турный режим в двиг теле.

втор ми н основе теоретического н лиз, проведенного с использов нием д $\mathrm{H}^{-}$ ных [11] было пок з но [12], что содерж ние оксидов углерод и зот в сост ве отр бот вших г зов зн чительно выше, чем в термодин мически р вновесной смеси при темпер туре выхлоп (900), которой должны соответствов ть ничтожно м лые концентр ции. ксиды углерод и зот в двиг теле обр зуются по ре кциям

$$
\begin{gathered}
2+2=2 \quad 2+566 \text { к ж, } \\
\mathrm{N}_{2}+\mathrm{O}_{2}=2 \mathrm{NO}-181 \mathrm{k} \text { ж/моль. }
\end{gathered}
$$

корости этих ре кций с понижением темпер туры з фронтом пл мени быстро сниж ются, р вновесные концентр ции т кже быстро уменьш ются, поскольку конст нты р вновесия н ходятся в сильной з висимости от темпер туры. виду этого, н конечную концентр цию, н блюд емую в отр бот вших г 3 х, определяющим обр зом влияет м ксим льн я темпер тур, достиг ем я в пл мени. ледует отметить, что оКсид зот может пр ктически н цело р сходов ться в ре кции

$$
2 \mathrm{NO}+2 \mathrm{CO}=\mathrm{N}_{2}+2 \mathrm{CO}_{2},
$$

т к к к р вновесие этой ре кции пр ктически н цело сдвинуто впр во ( $2750 \approx 10^{3,9}$, $\left.900 \approx 10^{33}[2]\right)$, но бл год ря высокой энергии ктив ции р сп д (по д нным [13] 632 к ж/моль) со снижением темпер туры г зов скорость ре кции резко п д ет (ре кция «з мор жив ется»), и он пр ктически не влияет н содерж ние оксид зот в отр бот вших г 3 х.

ким обр зом, с ростом содерж ния непредельных и ром тических углеводородов, и, соответственно, плотности топлив, темпер тур, р звив ющ яся в пл мени, увеличив ется, что приводит к росту выбросов с отр бот вшими г з ми оксидов углерод и зот .

висимость выбросов углеводородов и продуктов их неполного окисления от плотности моторных топлив. одерж ние углеводородов и их оксипроизводных в отр бот вших г 3 х бензиновых и дизельных двиг телей может определяться двумя p зными процесс ми. пристенном слое к меры сгор ния темпер тур и концентр ция кислород низки, и идет не горение, окислительный пиролиз. лиф тические углеводороды р сп д ются преимущественно до мет н, эт н, этилен и пропилен $[14,15]$, окисление этих продуктов д ет форм льдегид, цет льдегид, кролеин. ром тические углеводороды подверг ются конденс ции с обр зов нием полициклических ром тических углеводородов и н г $\mathrm{p}[16,17]$, их ч стичное окисление д ет фенолы. олщин пристенного слоя в $з$ висимости от конструкции двиг теля и режим его р боты сост вляет 0,05 - 0,38 мм [18].

сли ди метр и высот к меры сгор ния (цилиндр двиг теля) D и , толщин пристенного слоя h, то, при р вномерном р спределении топлив доля его, н ходящ яся в пристенном слое $\pi D H h: \pi D^{2} H / 4=4 H / D$, при $\mathrm{D}=90 \div 100$ мм и $\mathrm{h}=0.05 \div 0.38$ мм доля бензин в пристенном слое $0,2 \div 1,7 \%$, что по порядку величины соответствует н блюд емым выброс м углеводородов и их оксипроизводных бензиновыми двиг те- 
лями (при отсутствии к т литического нейтр лиз тор ). ри поп д нии н стенку неисп рившихся к пель топлив скорость исп рения пониж ется, т к к к темпер тур стенки зн чительно ниже темпер туры в г зовом объеме, в результ те количество продуктов неполного горения резко возр ст ет. еисп ряющейся ч сти бензин тем больше, чем выше содерж ние в бензине тяжелых хвостовых фр кций. о д нным, опубликов нным в [19] уменьшение темпер туры выкип ния $90 \%$ бензин от 182 до $138^{0}$ сниж ет выбросы углеводородов и их оксипроизводных н $22 \%$.

торой процесс обр зов ния углеводородов и их оксипроизводных, возможный в бензиновых двиг телях - обр зов ние при $\alpha=1$ лок льных объемов, в которых $\alpha<1$.

этом случ е т кже идет термоокислительный пиролиз (но при более высокой темпеp туре, чем в пристенном слое).

дизельном двиг теле п рци льное д вление кислород всегд велико и темпер тур в пристенном слое всегд выше вследствие более интенсивной перед чи тепл излучением, т к к к чернот пл мени выше. результ те выброс углеводородов дизельными двиг телями ниже, оксипроизводных выше, чем бензиновыми двиг телями.

лиф тические углеводороды р сп д ются термически и окисляются зн чительно быстрее, чем бензол, в лкилбензол х химически н иболее ст бильно бензольное кольцо. оэтому д же после доокисления отр бот вших г зов в к т литическом нейтр лиз торе доля бензол в общем содерж нии углеводородов выше, чем в бензине [20].

отр бот вших г 3 х содержится к к м лотоксичные, т к и высокотоксичные углеводороды и их оксипроизводные; м лотоксичные - мет н, эт н, этилен, пропилен в сумме сост вляют до $80 \%$ углеводородов и их оксипроизводных в отр бот вших г з х. дн ко, содерж тся в отр бот вших г з х и очень токсичные веществ : фенол, форм льдегид, цет льдегид, бенз $(\alpha)$ пирен. льдегиды, содерж щиеся в отр бот вших г 3 х, зн чительно токсичнее бензол, но в природных условиях время их жизни невелико, тогд к к бензол очень ст билен. ильнейший к нцероген бенз $(\alpha)$ пирен и его н логи (полициклические ром тические углеводороды) обр зуются при конденс ции моноциклических ром тических и их содерж ние в отр бот вших г 3 х тем больше, чем больше ром тических углеводородов содержится в бензине [21]. к, при горении бензол выбросы бенз $(\alpha)$ пирен до 26,0-28,6 р з больше, чем при горении гекс н гексен и циклогекс н (т блиц $3,[22])$.

лияние углеводородовн содерж ние бенз $(\alpha)$ пирен $(\mathrm{ppm})$ в отр бот вщих $2 ~ 3 x$

\begin{tabular}{|l|c|c|c|}
\hline \multirow{2}{*}{ глеводород } & \multicolumn{3}{|c|}{ оэффициент избытк воздух } \\
\cline { 2 - 4 } & 1,15 & 2,0 & 2,5 \\
\hline ензол & 28,6 & 429 & 335 \\
\hline иклогекс н & 1,1 & 33 & 54 \\
\hline ексен-1 & 1,0 & 32 & 31 \\
\hline екс н & 1,0 & 24 & 17 \\
\hline
\end{tabular}

ким обр зом, повышение плотности топлив , связ нное с увеличением содерж ния в нем непредельных и ром тических углеводородов, т кже с утяжелением фр кций бензин и дизельного топлив, увеличив ет вероятность поп д ния к пель топлив н стенку и, соответственно, долю ре кций, протек ющих в пристенном слое. то сниж ет обр зов ние продуктов полного горения топлив и увеличив ет выбросы недогоревших углеводородов и продуктов их неполного окисления и конденс ции. ри повышении плотности топлив увеличив ется не только общее содерж ние углеводородов в отр бот вших г 3 х, но и зн чительно возр ст ют выбросы н иболее токсичных из них - бензол и бенз $(\alpha)$ пирен .

висимость выбросов с жи от плотности моторных топлив. ж - продукт глубокого термического р сп д углеводородов. ри гомогенном горении в бензиновом двиг теле он обр зуется только при недост тке кислород $(\alpha<1)$ [23], что может н блюд ться в условиях к рбюр торного двиг теля, либо при детон ционном горении. ри диффузионном горении, ре лизуемом в дизельном двиг теле, с ж обр зуется всегд . ри горении к пель топлив п ры топлив , н грев ясь от фронт пл мени по

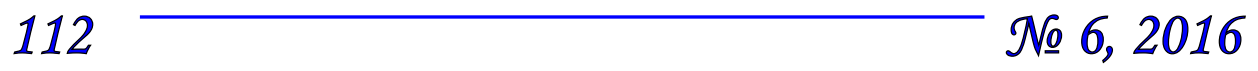


пути от поверхности к пли к пл мени, подверг ются глубокому пиролизу с обр зов нием с жи, котор я полностью или ч стично сгор ет в пл мени. ыход с жи из углерод углеводородного топлив увеличив ется с увеличением отношения : в углеводороде. о д нным [24] склонность углеводородов к обр зов нию с жи количественно х р ктеризуется рядом бензол : толуол : ксилол : мет н $=8.2: 6.6: 4.5: 1.0$. о д нным [25] склонность лк нов к обр зов нию с жи не з висит от числ томов углерод в молекуле, для других кл ссов углеводородов с увеличением числ томов углерод в молекуле (сниж ется : ) склонность к обр зов нию с жи уменьш ется; в ряду лк ны < лкены и моноциклические цикло лк ны < диены и бициклические цикло лк ны < рены < н фт лины - увеличив ется. 3 углеводородов, содерж щихся в бензине, н ибольший выход с жи д ет бензол. ри чисто термическом р зложении углеводородов (условия горения к пель топлив при движении п ров от поверхности к пли к фронту пл мени) обр зов ние с жи тормозится водородом, содерж ние которого в продукт х пиролиз тем меньше, чем больше ром тизов нность топлив . гоp ние ч стиц обр зов вшейся с жи и их г зифик ция идет в результ те ре кций

$$
\begin{aligned}
+2 & =2, \\
+2 & =+2, \\
+\quad 2 & =2 .
\end{aligned}
$$

зифик ция водой идет с конст нтой скорости примерно в 1,6 р 3 большей, чем диоксидом углерод [25]. ри топливе с меньшим отношением : (менее ром тизов нном) отношение $\left[\mathrm{H}_{2} \mathrm{O}\right]:\left[\mathrm{CO}_{2}\right]$ больше, что способствует более глубокой г зифик ции с жи. ким обр зом, выбросы с жи двиг телями внутреннего сгор ния тем больше, чем больше степень ром тизов нности моторного топлив , и соответственно, его плотность. бензин х н ибольший выход с жи при горении с недост тком воздух (или при детон ционном горении) д ет бензол; дизельные топлив д ют тем большее с жеобр зов ние, чем выше в них содерж ние конденсиров нных (би- и трициклических) ром тических углеводородов.

висимость эксплу $m$ ционных х $р$ ктеристик втомобилей от плотности применяемого топлив . овышение плотности топлив (при увеличении содерж ния в топливе непредельных и ром тических углеводородов; повышении конц кипения) приводит к росту н г рообр зов ния в двиг теле. оскольку в условиях двиг теля протек ют т кже ре кции окисления и г зифик ции н г р (ре кции (10)-(12)) - достиг ется некотор я р вновесн я толщин н г р , соотношение скоростей ре кций (10)-(12) и ре кции н г рообр зов ния определяют количество н г р в двиг теле.

г рообр зов ние повыш ет м ксим льную темпер туру в двиг теле, ввиду теплоизоляционных свойств н г р , что повыш ет вероятность возникновения детон ционного горения в бензиновых двиг телях [26]. г р предст вляет собой н лог окисленного нефтяного кокс , весьм ре кционно ктивен и склонен к с мовоспл менению при 330-360 ${ }^{0}$ [27]. ри сгор нии топливовоздушной смеси и выпуске продуктов сгоp ния н г р p ск ляется и вследствие низкой теплопроводности сохр няет высокую темпер туру при впуске новой порции топливовоздушной смеси. з имодействуя с кислородом, н г р обр зует «горячие точки», вызыв ющие преждевременное горение в т кте сж тия. то увеличив ет р сход энергии н сж тие и удельный р сход топлив , сниж ет мощность двиг теля, в бензиновых двиг телях еще в большей степени увеличив ет вероятность возникновения детон ции. ля обеспечения бездетон ционной p боты требуемое окт новое число бензин после обр зов ния н г $\mathrm{p}$ в двиг теле повыш ется, к к известно, н 10 и более пунктов $[20,28]$. г р приводит т кже к преждевременному выходу из строя свечей з жиг ния. ледует отметить, что увеличение удельного р сход и снижение мощности двиг теля происходят т кже вследствие зн чительного увеличения з тр т энергии н трение в двиг теле после обр зов ния н г р .

стр нение н г рообр зов ния в двиг теле, к к пок з но в $[8,9,12,29-32]$ зн чительно улучш ет к к эксплу т ционные, т к и экологические х $\mathrm{p}$ ктеристики втомо- 
билей. ким обр зом, кту льной з д чей является м ксим льно возможное снижение н г рообр зов ния з счет влияния н к чество применяемых топлив.

увеличением плотности топлив и пропорцион льного плотности поверхностного н тяжения ухудш ется смесеобр зов ние в двиг теле з счет увеличения среднего $\mathrm{p}$ 3мер к пель впрыскив емого топлив, что увеличив ет время его сгор ния. ростом плотности возр ст ет т кже вязкость топлив . ежду тем, увеличение вязкости дизельного топлив выше $\sim 6,5 \mathrm{mM}^{2} / \mathrm{c}$ при $20^{0}$ сниж ет 3 полняемость топливного плунжерного н coc , и его под ч сниж ется тем в большей степени, чем выше вязкость.

величение плотности дизельных топлив отриц тельно ск зыв ется н величине цет нового числ . ет новое число может быть подсчит но исходя из группового углеводородного сост в по ур внению (13), [3]:

$$
=0,85+0,1-0,2,
$$

где , и - содерж ние соответственно п р финовых, н фтеновых и ром тических углеводородов, м с.\%. ет новое число линейно сниж ется до 30 с ростом содерж ния ром тических углеводородов до $50 \%$ [3]. ким обр зом, увеличение содерж ния в топливе ром тических углеводородов, соответственно, плотности топлив , при прочих р вных условиях сниж ет величину цет нового числ .

ехнологические решения, н пр вленные н снижение плотности топлив. роведенный втор ми н лиз пок зыв ет, что повышение плотности применяемых бензинов и дизельных топлив нег тивно влияет н экологические и эксплу т ционные х p ктеристики втомобилей. роизводство топлив с плотностью, пониженной до миним льного зн чения, определяемого норм ми для д нной к тегории к честв [33], во3можно при смещении приоритетов нефтеперер б тыв ющей промышленности в н пр влении р звития процессов, обеспечив ющих миним льное содерж ние ром тических углеводородов в топливе.

еобходимо обяз тельное огр ничение содерж ние риформ т в бензине (принятое в ряде стр н) ввиду высокого содерж ния ром тических углеводородов в бензин х риформинг . ри этом требуем я величин окт нового числ при высоких экологических свойств х бензин может быть обеспечен $з$ счет повышения содерж ния изомериз т, что требует ускоренного р звития мощностей изомериз ции б л нсового количеств - $82^{\circ}\left(5^{-}{ }_{6}\right)$. то позволит снизить содерж ние в бензине ром тических углеводородов примерно в 1,5 р 3 [7].

ругим возможным, но зн чительно более з тр тным путем решения 3 д чи снижения содерж ния ром тических углеводородов при увеличении производств высокоокт новых бензинов является созд ние комплексов весьм зн чительных мощностей гидроочистк в куумного г зойля - к т литический крекинг +гидриров ние- лкилиров ние.

еобходимо н р щив ть мощности гидрокрекинг, продукты которого содерж т незн чительное количество ром тических углеводородов, при м ксим льном увеличении изо лк нов.

нижение плотности производимых топлив изменением соотношения мощностей нефтеперер ботки требует весьм зн чительных к пит льных з тр т, и доступно не для всех стр н. то же время, возможно снижение плотности и нек пит лоемкими метод ми.

дин из т ких методов - введение в бензины бут нов в предел х допустимого уровня д вления н сыщенных п ров, что позволит несколько снизить содерж ние ром тических углеводородов. то достиг ется регулиров нием процесс при прохождении бензин через ст билиз ционную колонну, и не требует к пит льных 3 тр т.

зменение плотности топлив возможно путем изменения темпер турного ди п зон выкип ния бензин и дизельного топлив (при прочих р вных условиях). ля бензинов для снижения содерж ния ром тических, и соответственно, плотности требуется снижение конц кипения до 150-160 ${ }^{\circ} \mathrm{C}$. ля дизельных топлив жел тельно снижение н ч л кипения до 150-60 ${ }^{\circ} \mathrm{C}$ и уменьшение конц кипения. то уменьшит соотношение $\mathrm{C}: \mathrm{H}, \quad$ соответственно и плотность топлив . роме общего снижения содерж ния ром тических углеводородов достиг ется зн чительное снижение содерж ния

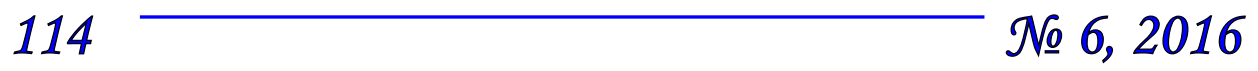


полициклических ром тических углеводородов и серы, т кже понизится темпер туp $з$ стыв ния, что весьм существенно для стр н с холодным клим том.

ледует отметить, что снижение плотности, связ нное со снижением содерж ния ром тических углеводородов в топлив х снизит моющие свойств . роме того, снижение конц кипения бензинов будет увеличив ть д вление н сыщенных п ров бензин, что приведет к увеличению потерь от исп рения. ребуемое обеспечение необходимого уровня моющих свойств, и снижение д вления н сыщенных п ров без осложнения смесеобр зов ния в двиг теле не может быть достигнуто метод ми нефтеперер ботки, и реш ется введением в бензины в к честве прис док поверхностно- ктивных веществ [34].

ег тивные экологические и эксплу т ционные последствия, связ нные с повышенной плотностью топлив, позволяют устр нить применение высокоэффективных прис док к топлив м, обеспечив ющих предотвр щение обр зов ния н г р в двиг теле $[6,12,29-32,35,36]$. то - быстроре лизуем я м лоз тр тн я льтерн тив , котор я позволяет решить проблему обеспечения экологической безоп сности и эффективности эксплу т ции втотр нспорт в кр тч йшие сроки.

ким обр зом, теоретически обоснов но нег тивное влияние повышенной плотности моторных топлив н экологические и эксплу т ционные х $\mathrm{p}$ ктеристики втомобилей. величение плотности связ но с повышенным содерж нием ром тических углеводородов и тяжелых фр кций, что приводит к росту выбросов токсичных веществ, с жи и углекислого г 3 , удельного р сход топлив и требов ний к окт новому числу бензин , сниж ет цет новое число дизельных топлив, ухудш ет смесеобр зов ние в двиг телях и увеличив ет н г рообр зов ние.

формулиров ны 3 д чи нефтеперер б тыв ющей промышленности по р сширению мощностей процессов, обеспечив ющих производство топлив с миним льными регл ментиров нными зн чениями плотности. редложены м лоз тр тные методы снижения плотности регулиров нием темпер турного ди п зон выкип ния бензин и дизельного топлив , введением бут нов и прис док к топлив м. е лиз ция комплекс предл г емых мероприятий позволит зн чительно повысить экологическую безоп сность и эффективность эксплу т ции втотр нспорт и других видов тр нспорт , потребляющих бензины и дизельные топлив .

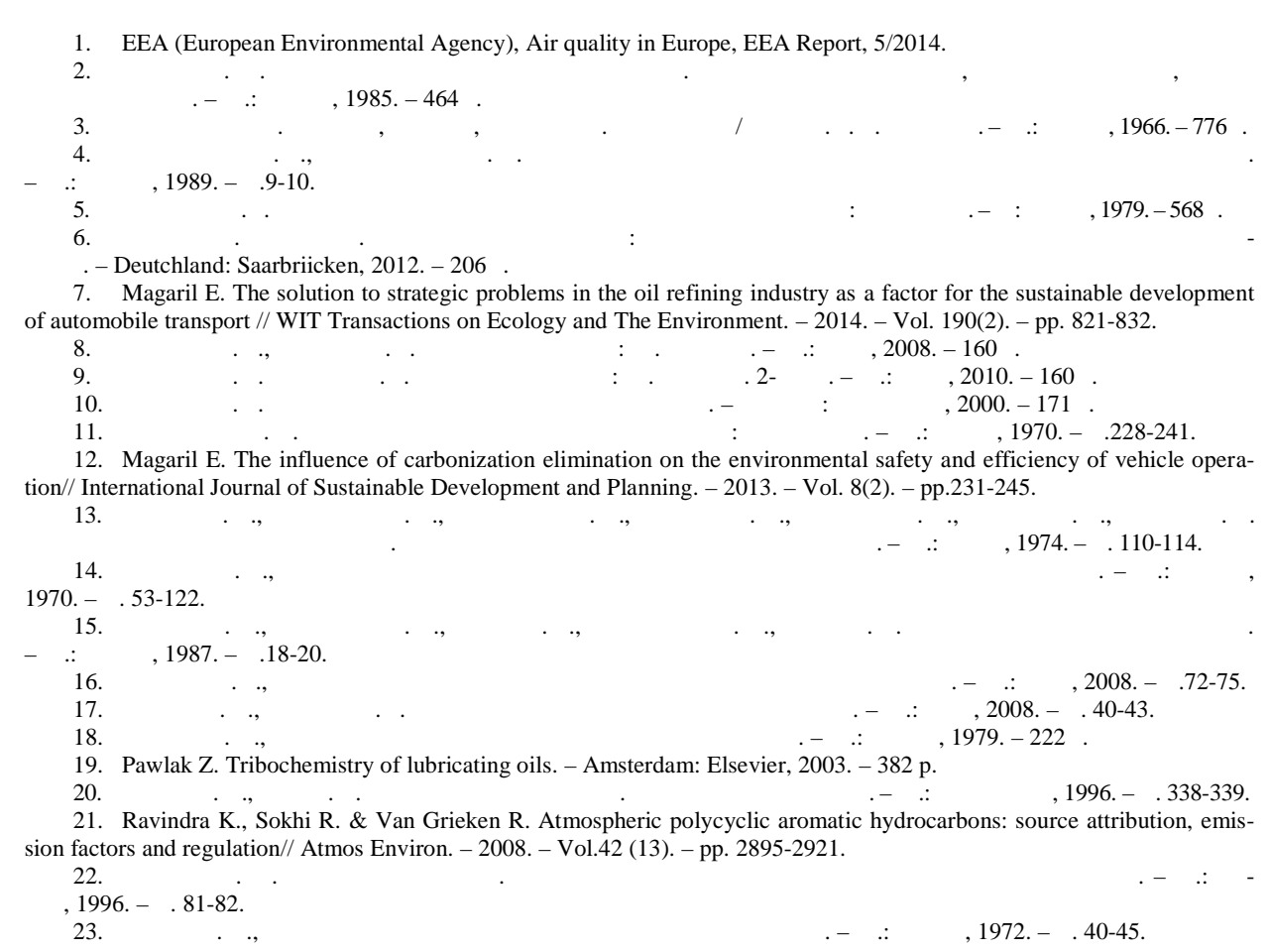


24. Tesner P. A., Shurupov S. V. Some physico-chemical parameters of soot formation during pyrolysis of hydrocarbons //Combustion Science and Technology. - 1995. - Vol 105(1-3). - pp. 147-161.

25. Chemistry and Physics of Carbon. Ed. by Philip L Walker Jr., Marcel Dekker, Inc., New York, 1965.

26. Magaril, E. R., Magaril, R. Z., Bamburov, V. G. Specific features of combustion in gasoline-driven internal combustion engines// Combustion, Explosion and Shock Waves. - 2014. - Vol.50 (1). - pp. 75-79.

27. юняев . . ефтяной углерод. - .. имия, 1980. $-124 \mathrm{c}$

28. рузе . ., тивенс . . ехнология перер ботки нефти. - .. имия, 1964. 414 с.

29 г рил . ., г рил . ., енд рев . ., орзун . . лияние н г рообр зов ния н экологическую безоп сность эксплу т ции втомобилей с бензиновыми двиг телями // звестия высших учебных 3 ведений. ефть и г 3. - 2011. - № 3. - . 85-88.

30 Magaril E. Improving the efficiency and environmental safety of gasoline engine operation// WIT Transactions on Built Environment. - 2013. - Vol. 130. - pp. 437-485.

31 Magaril E. Carbon-free gasoline engine operation// International Journal of Sustainable Development and Planning. - 2015. - Vol. 10(1). - pp. 100-108.

32 г рил . ., г рил . ., мбуров . ., ушин . ., енд рев . . щитно-к т литический н нослой для бензиновых двиг телей внутреннего сгор ния // имическ я технология. - 2011. - . 12. - № 8. - . 485-490.

33 Worldwide Fuel Charter, 5th edition, 2013, http://www.acea.be/collection/publications.

34 Magaril E. R. Reducing gasoline loss from evaporation by the introduction of a surface-active fuel additive// WIT Transactions on the Built Environment. - 2015. - Vol. 146. - pp. 233-242.

35 Magaril E. Improving car environmental and operational characteristics using a multifunctional fuel additive// WIT Transactions on Ecology and the Environment. - 2011. - Vol. 147. - pp. 373-384.

36 г рил . ., г рил . . овышение экологической безоп сности и эффективности эксплу т ции втотр нспорт применением прис дки к топлив м// р нспорт р л . - 2014. - № 2 (41). - . 84-89.

\section{ведения об втор $x$}

г рил лен оменовн, д. т. н., профессор, 3 ведующий к федрой « кономик природопользов ния», р льский федер льный университет имени первого резидент оссии . . льцин, г. к теринбург, тел. +7(343)3743320,e-mail: magaril67@mail.ru

г рил омен еликович, Ә. т. н., профессор, гл вный н учный сотрудник к федры «ерер ботк нефти и 2 з », юменский индустри льный университет, г. юмень, тел. +7(3452)256925, e-mail png@tsogu.ru

\section{Information about the authors}

Magaril E. R., professor, Doctor of Engineering, head of the chair "Environmental Economics», Ural Federal University named after the first President of Russia B. N. Yeltsin, Yekaterinburg, phone: +7(343) 3743320, e-mail: magaril67@mail.ru

Magaril R. Z., Doctor of Engineering, professor, senior researcher of the chair "Oil and Gas Processing», the Indus trial University of Tyumen, phone: +7(3452)256925, e-mail: png@tsogu.ru 